\title{
Influence of Intercritical Annealing Temperature on Microstructure and Mechanical Properties of a Cold-Rolled Medium-Mn Steel
}

\author{
Yan Ma ${ }^{1}$ (D), Wenwen Song ${ }^{1, *(\mathbb{D})}$, Shixin Zhou ${ }^{1}$, Alexander Schwedt ${ }^{2}$ and Wolfgang Bleck ${ }^{1}$ \\ 1 Steel Institute (IEHK), RWTH Aachen University, Intzestraße 1, 52072 Aachen, Germany; \\ yan.ma@iehk.rwth-aachen.de (Y.M.); shixin.zhou@rwth-aachen.de (S.Z.); bleck@iehk.rwth-aachen.de (W.B.) \\ 2 Central Facility for Electron Microscopy (GFE), RWTH Aachen University, Ahornstraße 55, \\ 52074 Aachen, Germany; schwedt@gfe.rwth-aachen.de \\ * Correspondence: wenwen.song@iehk.rwth-aachen.de; Tel.: +49-241-809-5815
}

Received: 27 April 2018; Accepted: 14 May 2018; Published: 15 May 2018

\begin{abstract}
Medium-Mn steels are characterized by ultrafine-grained (UFG) duplex microstructure consisting of ferrite and a large amount of retained austenite. Intercritical annealing is of great importance to achieving the UFG duplex microstructure and adjusting amount as well as stability of retained austenite. In the present work, the influence of intercritical annealing temperature on the microstructure and mechanical properties was investigated in a cold-rolled medium-Mn steel Fe-12Mn-3Al-0.05C. Particularly, the dependence of microstructural morphology on intercritical annealing temperature was emphasized to reveal the genesis of the microstructural morphology in medium-Mn steels. The ferrite-austenite duplex microstructure manifested an elongated morphology in the specimen annealed at $555{ }^{\circ} \mathrm{C}$, which inherited the lath structure of the cold-rolled state. The medium-Mn steel exhibited a continuous yielding behavior and a relatively low strain-hardening rate. With an increase in intercritical annealing temperature up to $650{ }^{\circ} \mathrm{C}$, the amount of retained austenite increased and microstructure was partially recrystallized, showing a mixture of elongated and equiaxed grain morphologies. When the intercritical annealing was applied at $700{ }^{\circ} \mathrm{C}$, the medium-Mn steel mainly exhibited recrystallized microstructure with equiaxed morphology. The optimal balance between the amount and the stability of retained austenite led to an enhancement of strain hardening and ductility. With a further increase in the intercritical annealing temperature to $750{ }^{\circ} \mathrm{C}$, the medium-Mn steel possessed pronounced strain-hardening behavior at the beginning of the tensile deformation with deteriorated ductility.
\end{abstract}

Keywords: medium-Mn steels; intercritical annealing; austenite reverse transformation; retained austenite; transformation-induced plasticity; recrystallization; strain-hardening behavior

\section{Introduction}

The lightweight concept in the automotive industry promotes the progressive development of advanced high strength steels (AHSS) [1]. The first-generation AHSS with ferritic matrix possess limited combination of strength and ductility, yielding in a product of ultimate tensile strength (UTS) and total elongation (TEL) of about $20 \mathrm{GPa} \%[2,3]$, while the second-generation AHSS with austenitic matrix offer extraordinary high strength (UTS > $800 \mathrm{MPa}$ ) and superior ductility (TEL up to $\sim 80 \%$ ) [4-6]. However, the high alloying concentration and sophisticated metallurgy processes hinder the industrial production of the second-generation AHSS [6,7]. Recently, the third-generation AHSS have drawn a considerable amount of attention because of the convenient combination of production cost and mechanical properties [4,7]. Medium-Mn steels containing 3-12 wt \% Mn become one of the most promising candidates in the third-generation AHSS, showing great potential for 
future automotive applications. The most common alloy systems of medium-Mn steels include Fe-Mn-C system [8-11], Fe-Mn-Al-C system [12,13] and Fe-Mn-Al-Si-C system [14-16]. In contrast to the microstructure of the first-generation and second-generation AHSS, medium-Mn steels are characterized by ultrafine-grained (UFG) duplex microstructure containing ferrite and a large amount of retained austenite $[7,9,11,17-19]$. In literature, the ferrite-austenite duplex microstructure has been intensively studied in duplex stainless steels [20-23]. The retained austenite transforms into $\alpha^{\prime}$-martensite or/and twins during deformation. The transformation-induced-plasticity (TRIP) effect and the twinning-induced-plasticity (TWIP) effect promote a high strain-hardening rate and enhance ductility of medium-Mn steels [3,7,24].

The previous studies pointed out that the intercritical annealing, which is also known as austenitereverted-transformation (ART) annealing [17], plays an essential role in achieving desirable microstructure and excellent mechanical properties of medium-Mn steels. Extensive research has focused on the influence of intercritical annealing parameters (intercritical annealing temperature [9,25-28], intercritical annealing time [11,29], austenitization temperature [30,31], and heating rate in intercritical annealing [32] etc.) on microstructure and mechanical properties of medium-Mn steels. It was reported that the intercritical annealing temperature is of significant importance for the amount and stability of retained austenite $[9,27,28,33]$. An increase in intercritical annealing temperature in a certain range results in an increase in austenite fraction without much deterioration of austenite stability; meanwhile, the stacking fault energy (SFE) of austenite is increased $[9,26]$. In the previous research, it was stated that intercritical annealing time has a slight effect on microstructure, with respect to the grain size, during austenite reversion [34,35]. The thickness of the austenite lath increased slowly with an increase in intercritical annealing time [29]. Besides, it was found that the austenitization temperature has a strong influence on the morphology of quenched martensite [30,31]. This directly affected the austenite reverted transformation, such as the austenite volume fraction, transformation rate and grain size [30,31].

In general, the morphology of medium-Mn steels is controlled by the initial microstructure. It was reported that the hot-rolled or austenitized medium-Mn steels exhibit an elongated morphology after intercritical annealing [8,36-41], inheriting the morphology of martensite. In contrast, the cold-rolled medium-Mn steels usually manifest an equiaxed grain morphology after intercritical annealing $[8,37,40-43]$. It seems that the cold rolling prior to the intercritical annealing provides a driving force for recrystallization, which significantly affects the microstructural morphology of medium-Mn steels. However, the genesis of microstructural morphology in medium-Mn steel is still not well understood. Moreover, the influence of the intercritical annealing temperature on the recrystallization behavior of cold-rolled medium-Mn steels is rarely reported. In the present study, the microstructure and mechanical properties were investigated in a cold-rolled medium-Mn steel intercritically annealed at different temperatures. In particular, the intercritical annealing was applied in a large temperature range from $555^{\circ} \mathrm{C}$ to $750{ }^{\circ} \mathrm{C}$, in order to reveal the recrystallization behavior and elucidate the genesis of the microstructural morphology of the medium-Mn steels.

\section{Material and Methods}

The chemical composition of the investigated medium-Mn steel Fe-12Mn-3Al-0.05C is presented in Table 1. The laboratory-melt alloy was cast into an ingot, followed by hot rolling at $1150{ }^{\circ} \mathrm{C}$. During the hot rolling process, the thickness of the ingot was progressively reduced from $40 \mathrm{~mm}$ to $2.5 \mathrm{~mm}$. Subsequently, the steel sheets were homogenized at $1100{ }^{\circ} \mathrm{C}$ for two hours, followed by water quenching. Then the steel was austenitized at $850{ }^{\circ} \mathrm{C}$ for $10 \mathrm{~min}$, followed by water quenching. Cold rolling was conducted subsequently with a reduction in thickness of about $50 \%$. Bone-shaped tensile test specimens were cut from $1.25 \mathrm{~mm}$ thick cold-rolled steel sheet. The $\mathrm{A}_{1}$ and $\mathrm{A}_{3}$ temperatures of the medium-Mn steel were predicted by Thermo-Calc package with the database TCFE9. The $\mathrm{A}_{1}$ and $\mathrm{A}_{3}$ temperatures are approx. $500{ }^{\circ} \mathrm{C}$ and $760{ }^{\circ} \mathrm{C}$, respectively. The tensile specimens were subject to intercritical annealing in a salt bath at different temperatures, namely $555^{\circ} \mathrm{C}, 600{ }^{\circ} \mathrm{C}, 650^{\circ} \mathrm{C}, 700^{\circ} \mathrm{C}$, 
and $750^{\circ} \mathrm{C}$, for $12 \mathrm{~h}$, followed by quenching in water at room temperature. The cold-rolled specimen is referred to as CR and the annealed specimens are referred to as IA555, IA600, IA650, IA700, and IA750 according to the intercritical annealing temperature. The processing schedule after hot rolling and the nomenclature of the individual sheets are provided in Figure 1.

The tensile tests under quasi-static condition were carried out in a Z4204 tensile machine (Zwick GmbH \& Co. KG, Ulm, Germany) at room temperature at a constant strain rate of $0.001 \mathrm{~s}^{-1}$. The geometry of the bone-shaped tensile specimen is illustrated in Figure 2. The initial length $\left(\mathrm{L}_{0}\right)$ was set to $20 \mathrm{~mm}$ in the middle part of the gauge to measure the elongation. The elongation of a specimen was measured by optical strain measurement with a video extensometer. Three tests were performed under each annealing condition for reasonable statistics.

Table 1. Chemical composition (in wt \%) of the investigated medium-Mn steel Fe-12Mn-3Al-0.05C.

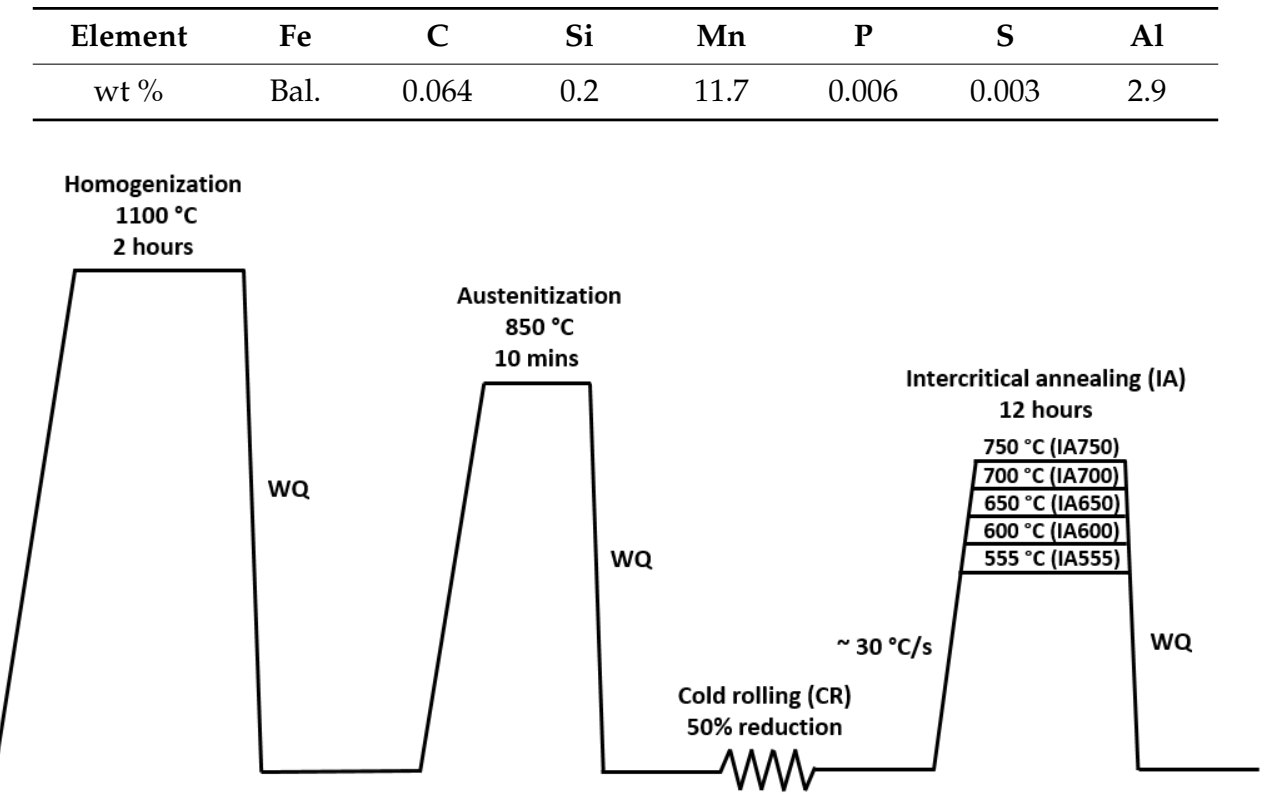

Figure 1. Processing schedule of the medium-Mn steel after hot rolling.

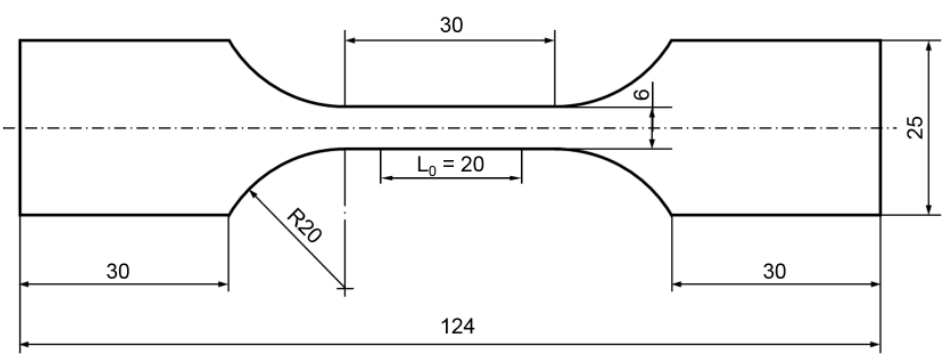

Figure 2. Geometry of bone-shaped tensile specimen (unit: $\mathrm{mm}$ ).

The microstructure of the steel after intercritical annealing was characterized by a Zeiss Sigma field-emission scanning electron microscope (SEM) (Carl Zeiss Microscopy GmbH, Jena, Germany). The metallographic specimens for SEM observation were electropolished after the mechanical grinding and polishing. Subsequently, the specimens were etched with $3 \%$ Nital. Electron backscattered diffraction (EBSD) was performed in the electropolished state using a JSM 7000F field-emission SEM (JEOL Ltd., Tokyo, Japan) equipped with a Hikari EBSD camera and the collection software OIM DataCollection V7.3, both by AMETEK-EDAX (Mahwah, NJ, USA). The EBSD data were measured using electron energies of $20 \mathrm{keV}$ and a beam current of approx. $30 \mathrm{nA}$. Measurements were conducted 
in fields of $75 \mu \mathrm{m} \times 75 \mu \mathrm{m}$ with a step size of $50 \mathrm{~nm}$. After the measurements, the data were evaluated using OIM Analysis V8.0 by AMETEK-EDAX.

A power diffractometer Stadi MP (STOE, Darmstadt, Germany) with Mo $\mathrm{K}_{\alpha 1}$ radiation source $\left(\lambda_{M o,} K_{\alpha 1}=0.70930 \AA\right)$ was used to evaluate the amount of austenite in the annealed and deformed specimens. The experiments were performed on flat pieces of steel in reflection geometry according to Bragg-Brentano. A position-sensitive microstrip X-ray detector Mythen $1 \mathrm{~K}(450 \mu \mathrm{m}$, Dectris) with steps of $0.015^{\circ}$ (2-Theta) recorded the scattered intensities. The volume percentage of retained austenite was calculated by the following equation [44]:

$$
V_{\gamma}=\frac{I_{\gamma}^{220}+I_{\gamma}^{311}}{R_{\gamma}^{220}+R_{\gamma}^{311}} /\left(\frac{I_{\gamma}^{220}+I_{\gamma}^{311}}{R_{\gamma}^{220}+R_{\gamma}^{311}}+\frac{I_{\alpha}^{200}+I_{\alpha}^{211}}{R_{\alpha}^{200}+R_{\alpha}^{211}}\right) \times 100
$$

where, $I^{h k l}$ is the integrated intensity of austenite $(\gamma)$ or ferrite $(\alpha)$ peaks according to the crystallographic planes $\{\mathrm{hkl}\}$, while $R^{h k l}$ is the corresponding material specific factor. The $R$ value is determined by the crystal structure, composition and the diffraction planes $\{\mathrm{hkl}\}$ [44]. The $R$ values for Mo radiation source were $R_{\gamma}^{220}=376.7, R_{\gamma}^{311}=390, R_{\alpha}^{200}=288.6$, and $R_{\alpha}^{211}=530$ [44].

\section{Results}

\subsection{Microstructure Analysis of the Intercritically Annealed Specimens}

Figure 3 displays the microstructure images of the medium-Mn steel Fe-12Mn-3Al-0.05C in cold-rolled and intercritically annealed states. The cold-rolled specimen (Figure 3a) contained mainly deformed martensite, revealing an elongated morphology. When the cold-rolled medium-Mn steel was subject to intercritical annealing, austenite reversion took place. The specimen annealed at $555^{\circ} \mathrm{C}$ manifested duplex microstructure consisting of ferrite (grey flat regions) and austenite (dark crevices). The microstructure showed an elongated morphology (Figure 3b), which inherited the morphology of deformed martensite. With an increase in intercritical annealing temperature to $600{ }^{\circ} \mathrm{C}$ and $650{ }^{\circ} \mathrm{C}$, the microstructure of the medium-Mn steel revealed a mixture of elongated and equiaxed morphologies (Figure $3 c, d$ ), indicating the microstructure was partially recrystallized in this temperature range. When intercritical annealing temperature further increased to $700{ }^{\circ} \mathrm{C}$ and $750{ }^{\circ} \mathrm{C}$, the elongated microstructure vanished. The microstructure was fully recrystallized at those temperatures, resulting in equiaxed ferrite and retained austenite (Figure 3e,f). Some martensite was distinguished within the austenite grains when the material was annealed at $700{ }^{\circ} \mathrm{C}$ and $750{ }^{\circ} \mathrm{C}$. Thus, the high intercritical annealing temperature led to a large amount of austenite with poor thermal stability. This austenite might transform into fresh $\alpha^{\prime}$-martensite during quenching. In addition, the microstructure of the investigated steel was coarsened by an increase in intercritical annealing temperature.

In order to characterize the microstructure in the medium-Mn steel annealed at $555{ }^{\circ} \mathrm{C}$ and $700{ }^{\circ} \mathrm{C}$ in detail, EBSD was employed with respect to the phase distribution, kernel average misorientation (KAM) and texture analyses. Figure 4a,e illustrate the phase distribution in the specimens annealed at $555^{\circ} \mathrm{C}$ and $700{ }^{\circ} \mathrm{C}$, respectively. Both specimens contained UFG ferrite and austenite. The average grain size of ferrite and austenite is about $589 \mathrm{~nm}$ and $358 \mathrm{~nm}$ in the specimen annealed at $555{ }^{\circ} \mathrm{C}$, and approx. $1.19 \mu \mathrm{m}$ and $1.28 \mu \mathrm{m}$ in the specimens annealed at $700^{\circ} \mathrm{C}$. In addition, the microstructure of both specimens showed different morphologies and the amount of austenite. In the steel annealed at $555{ }^{\circ} \mathrm{C}$, there existed an elongated morphology of the ferrite-austenite duplex microstructure and approx. $17 \%$ austenite was indexed in the phase map (Figure 4a). Nevertheless, a considerable number of tiny regions were not properly indexed by EBSD, which are displayed by black color in the phase map (Figure 4a). The phase in these regions most probably is reverted austenite between ferrite laths. The retained austenite might be extremely fine and its size was even within the step size of EBSD measurement. Moreover, the sample was electropolished, and the shadowing effect from the topography of specimen surface might generate some difficulties for the identification of tiny austenitic 
phase nucleated in between of ferrite laths. The loss of the tiny austenite during phase indexing by EBSD might result in an underestimation of the austenite fraction. In contrast, the ferrite-austenite duplex microstructure with an equiaxed morphology was obtained with a large amount of retained austenite (around 61\%) in the steel annealed at $700{ }^{\circ} \mathrm{C}$ (Figure $4 \mathrm{e}$ ).
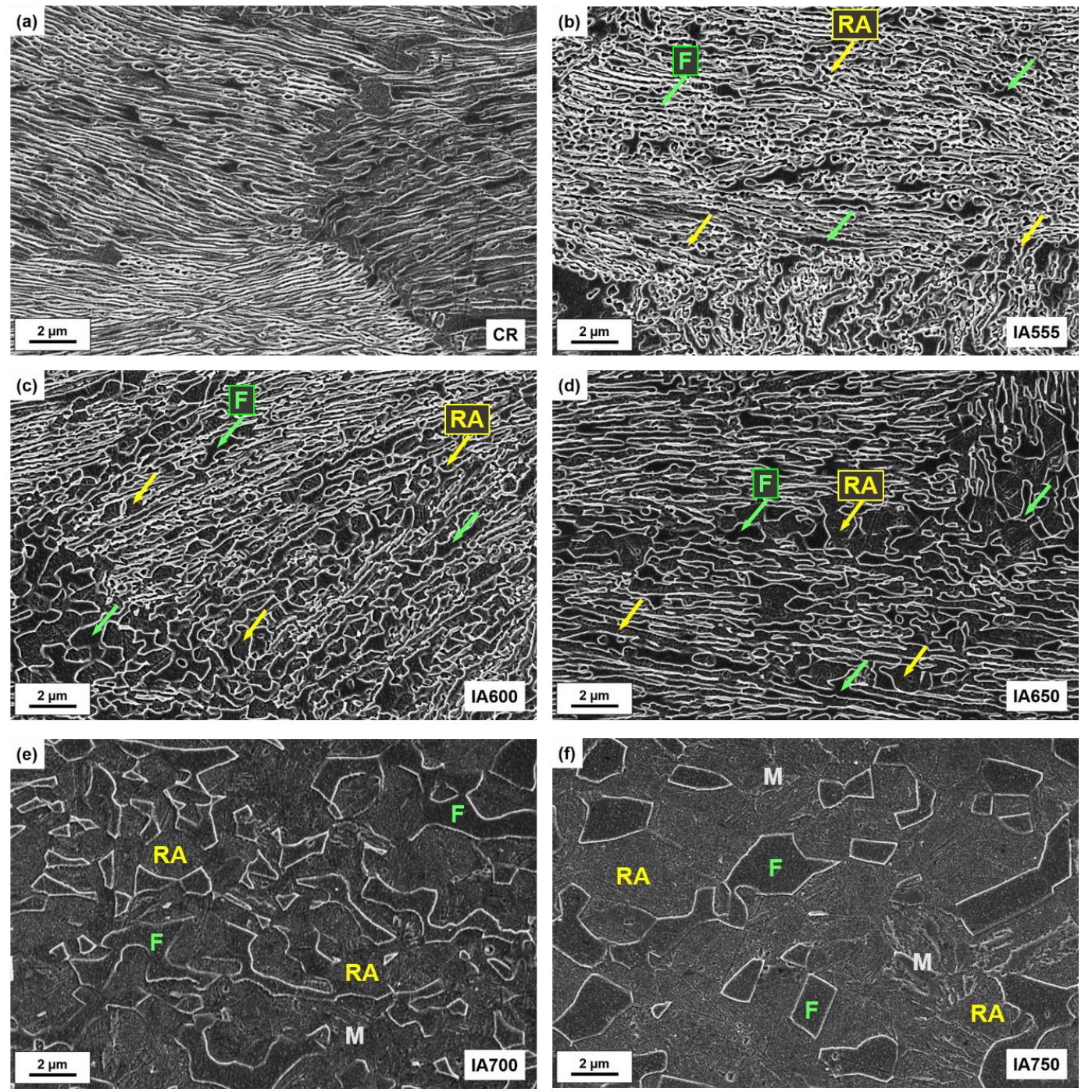

Figure 3. SEM images of the medium-Mn steel Fe-12Mn-3Al-0.05C in (a) CR state; (b) IA555 state; (c) IA600 state; (d) IA650 state; (e) IA700 state; and (f) IA750 state. CR stands for cold-rolled, IA for intercritical annealing, RA for retained austenite, F for ferrite, and $\mathrm{M}$ for martensite.

In respect of the KAM distribution, the steel annealed at $555{ }^{\circ} \mathrm{C}$ (Figure $4 \mathrm{~b}$ ) showed higher overall values than the steel annealed at $700{ }^{\circ} \mathrm{C}$ (Figure $4 \mathrm{f}$ ). This indicates a higher number of stored geometrically necessary dislocations (GND) in the specimen annealed at $555^{\circ} \mathrm{C}$, compared with the specimen annealed at $700{ }^{\circ} \mathrm{C}$. However, there were some regions in the steel annealed at $700{ }^{\circ} \mathrm{C}$ showing relatively higher KAM values than those in the other regions, which were also correlated with relatively smaller grain size. The formation of fresh $\alpha^{\prime}$-martensite in the thermally unstable austenite during quenching process might be responsible for the high KAM value in these regions. The inverse pole figure (IPF) maps (Figure $4 \mathrm{c}, \mathrm{d}$ ) in the steel annealed at $555{ }^{\circ} \mathrm{C}$ indicated a strong rolling texture of both austenite and ferrite. However, the texture of austenite (Figure $4 \mathrm{~g}$ ) was much more random in the steel annealed at $700{ }^{\circ} \mathrm{C}$, compared with ferrite (Figure $4 \mathrm{~h}$ ). The detailed analysis of texture evolution during austenite reversion is needed in a larger detection area in the future. 


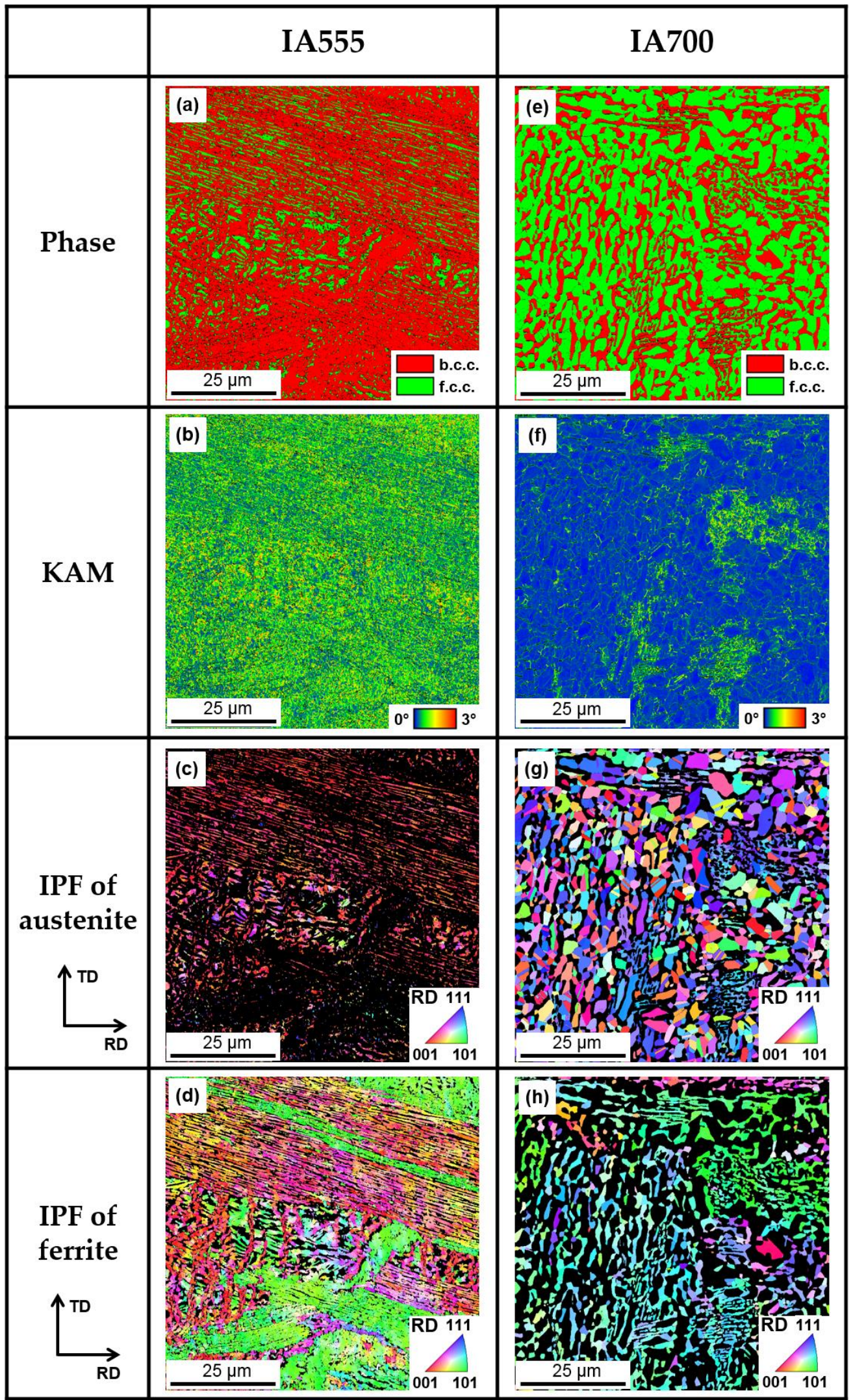

Figure 4. Electron backscattered diffraction (EBSD) maps of the medium-Mn steel annealed at $555^{\circ} \mathrm{C}$ and $700{ }^{\circ} \mathrm{C}$. (a,e) phase map; (b,f) kernel average misorientation (KAM) map with respect to a radius of $100 \mathrm{~nm} ;(\mathbf{c}, \mathbf{g})$ inverse pole figure (IPF) maps of austenite; (d,h) IPF maps of ferrite. 


\subsection{Amount of Retained Austenite in the Intercritically Annealed Specimens}

The XRD profiles of the medium-Mn steel Fe-12Mn-3Al-0.05C under cold-rolled and intercritically annealed conditions are shown in Figure 5a. In the cold-rolled state, only three peaks of body-centered cubic (b.c.c.) lattice structure existed in the XRD profile, revealing a martensitic structure in the cold-rolled state. When intercritical annealing was applied to the cold-rolled state, the peaks of face-centered cubic (f.c.c.) structure appeared in the XRD profiles, meaning that intercritical annealing results in austenite reversion. The amount of retained austenite as a function of intercritical annealing temperature of the medium-Mn steel is revealed in Figure 5b. The amount of retained austenite achieved $42.2 \mathrm{vol} \%$ in the specimen annealed at $555^{\circ} \mathrm{C}$ and increased to $58.4 \mathrm{vol} \%$ with an increase in intercritical annealing temperature up to $700{ }^{\circ} \mathrm{C}$. A further increase in intercritical annealing temperature to $750{ }^{\circ} \mathrm{C}$ led to a decrease in the amount of retained austenite to $34.9 \mathrm{vol} \%$. The decrease in austenite amount might be related to the formation of a certain amount of fresh $\alpha^{\prime}$-martensite during quenching in water at room temperature. Since, a high intercritical annealing temperature led to a poor thermal stability of retained austenite. Nevertheless, the amount of $\alpha^{\prime}$-martensite was not able to be quantified by XRD in this study. Because the peaks of $\alpha^{\prime}$-martensite (body-centered tetragonal, b.c.t.) and ferrite (b.c.c.) were overlapped, due to their similarity in crystal structures.
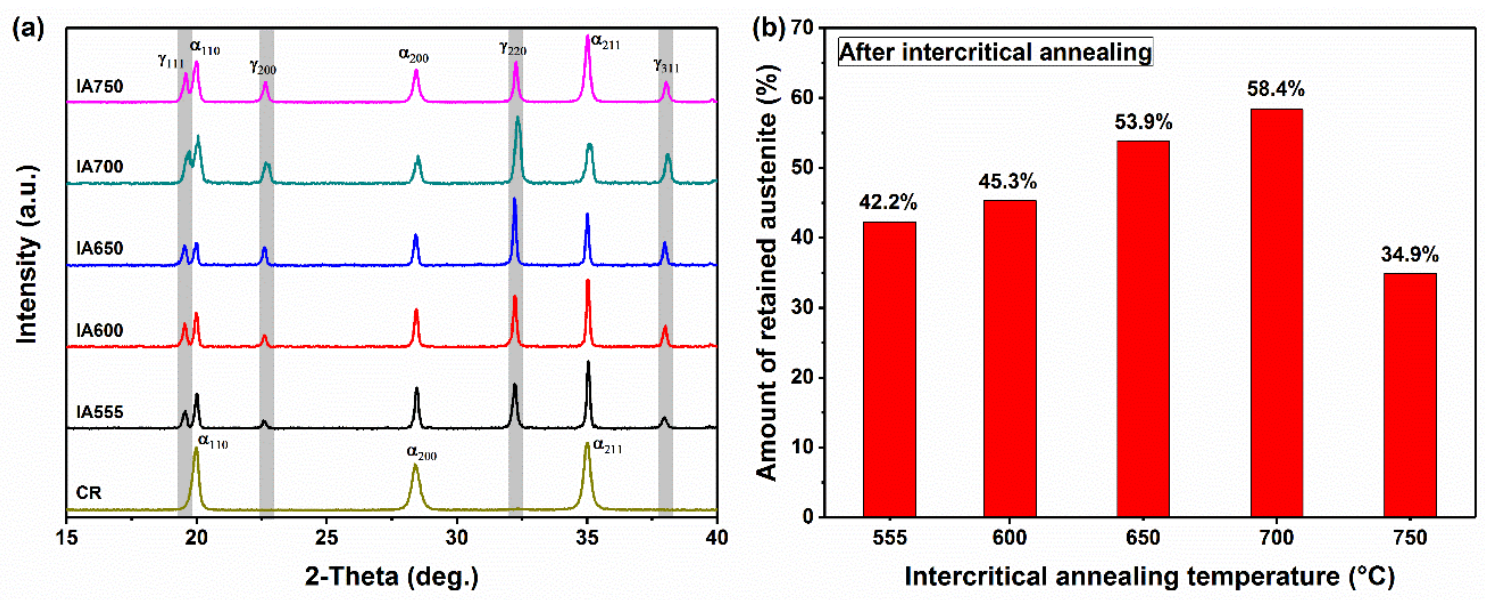

Figure 5. (a) XRD profiles of the medium-Mn steel Fe-12Mn-3Al-0.05C after cold rolling and intercritical annealing at temperature between $555{ }^{\circ} \mathrm{C}$ and $750{ }^{\circ} \mathrm{C}$; (b) the amount of retained austenite in the medium-Mn steel dependent of intercritical annealing temperature.

\subsection{Mechanical Properties}

Figure 6 shows the engineering stress-engineering strain curves of the medium-Mn steel Fe-12Mn-3Al-0.05C under cold-rolled and intercritically annealed conditions. The cold-rolled specimen possessed high yield strength of about $1400 \mathrm{MPa}$, but only small ductility. Intercritical annealing significantly improved ductility of the material with a sacrifice of yield strength. The engineering stress-engineering strain curve of the specimen annealed at $555{ }^{\circ} \mathrm{C}$ displayed a continuous yielding feature and relatively poor strain-hardening behavior. With an increase in intercritical annealing temperature to $600{ }^{\circ} \mathrm{C}$, the specimens showed discontinuous yielding behavior with a little amount of localized deformation after yielding. The specimens annealed above $650{ }^{\circ} \mathrm{C}$ did not manifest an obvious discontinuous yielding and localized deformation behavior. It can be seen that an increase in intercritical annealing temperature resulted in improved strain-hardening behavior and ductility of the medium-Mn steel. When the specimen was annealed at $750{ }^{\circ} \mathrm{C}$, it showed high ultimate tensile strength with reduced ductility. 


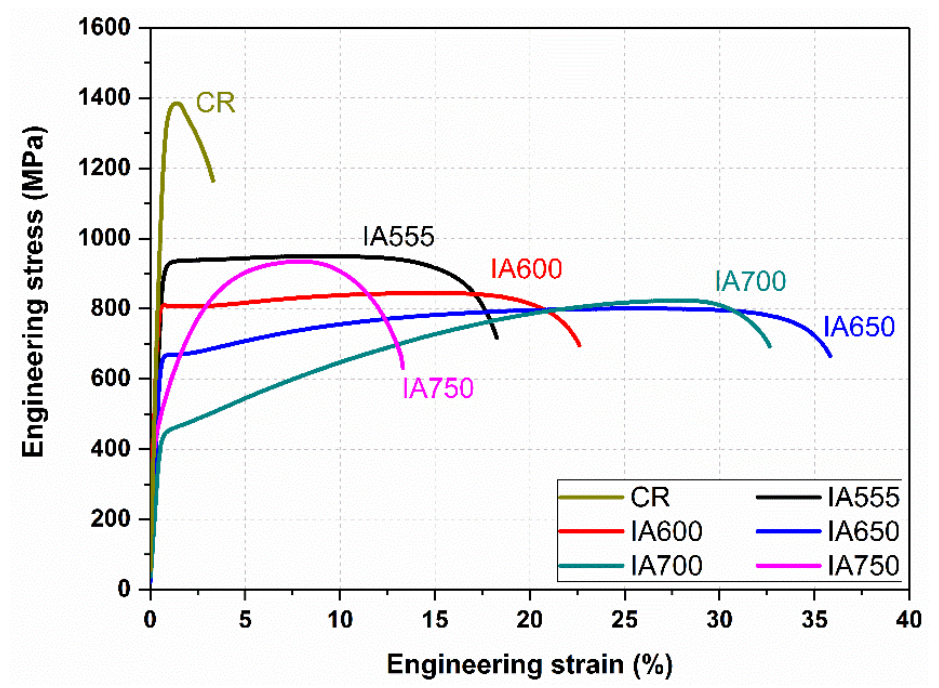

Figure 6. Engineering stress-engineering strain curves of the medium-Mn steel Fe-12Mn-3Al-0.05C after cold rolling (CR) and intercritical annealing at different temperatures (IA555, IA600, IA650, IA700 and IA750).

Figure 7 illustrates the mechanical properties as a function of intercritical annealing temperature in the investigated medium-Mn steel. An increase in intercritical annealing temperature from $555{ }^{\circ} \mathrm{C}$ to $700{ }^{\circ} \mathrm{C}$ resulted in a softening of material and an enhancement of ductility. The yield strength $\left(\mathrm{R}_{\mathrm{p} 0.2}\right)$ of the medium-Mn steel dropped from $\sim 900 \mathrm{MPa}$ to $\sim 430 \mathrm{MPa}$. Meanwhile, the ultimate tensile strength $\left(\mathrm{R}_{\mathrm{m}}\right)$ decreased from $\sim 940 \mathrm{MPa}$ to $\sim 790 \mathrm{MPa}$. The uniform elongation $\left(\mathrm{A}_{\mathrm{u}}\right)$ and the total elongation $\left(\mathrm{A}_{20}\right)$ were improved from $\sim 8 \%$ to $\sim 29 \%$ and $\sim 17 \%$ to $\sim 35 \%$, respectively. A further increase in intercritical annealing temperature to $750{ }^{\circ} \mathrm{C}$ led to an increase in strength, but a significant loss of ductility. The yield strength $\left(\mathrm{R}_{\mathrm{p} 0.2}\right)$ increased slightly to $440 \mathrm{MPa}$, and the ultimate tensile strength $\left(\mathrm{R}_{\mathrm{m}}\right)$ rose strongly to $940 \mathrm{MPa}$; however, the uniform elongation $\left(\mathrm{A}_{\mathrm{u}}\right)$ and the total elongation $\left(\mathrm{A}_{20}\right)$ dropped dramatically to $\sim 8 \%$ and $\sim 13 \%$, respectively.
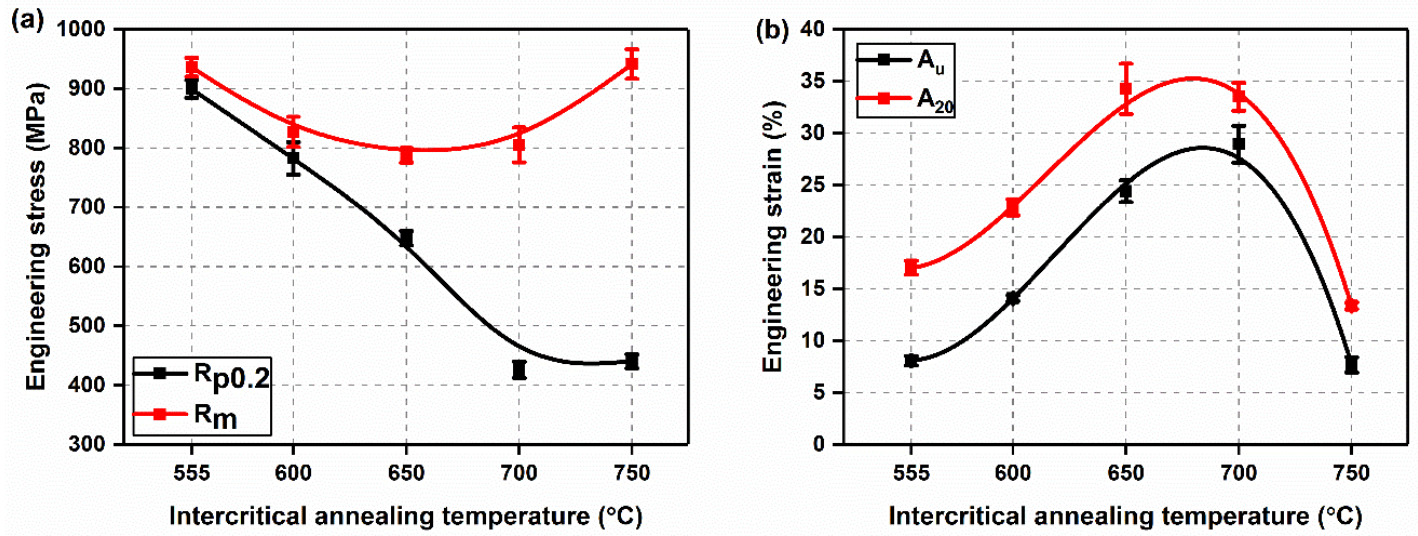

Figure 7. (a) Yield strength $\left(R_{\mathrm{p} 0.2}\right)$ and ultimate tensile strength $\left(\mathrm{R}_{\mathrm{m}}\right)$; $(\mathrm{b})$ uniform elongation $\left(\mathrm{A}_{\mathrm{u}}\right)$ and total elongation $\left(\mathrm{A}_{20}\right)$ of the medium-Mn steel Fe-12Mn-3Al-0.05C as a function of intercritical annealing temperature.

Figure 8 shows the true stress-true strain curves and corresponding strain-hardening rates of the medium-Mn steel annealed at various temperatures. The strain-hardening behavior of the specimens mainly manifested three different stages, except the specimen annealed at $750{ }^{\circ} \mathrm{C}$. In stage I, the strain-hardening rate of the medium-Mn steel was extremely high, albeit it decreased dramatically. 
In the specimen annealed at $600{ }^{\circ} \mathrm{C}$, the strain-hardening rate even dropped significantly below zero, which was correlated to the discontinuous yielding and localized deformation region in the engineering stress-engineering strain curve (Figure 6). In stage II, the strain-hardening rate revealed an increasing tendency with applied strain. After a pronounced increase, the strain-hardening rate decreased progressively with an increase in true strain in stage III. The specimen annealed at $750{ }^{\circ} \mathrm{C}$ showed pronounced strain-hardening behavior during the onset of plastic deformation, indicated by an intensely high strain-hardening rate; however, it declined dramatically up to necking. The level of strain-hardening rate increased with an increase in intercritical annealing temperature. In the specimen annealed at $555{ }^{\circ} \mathrm{C}$, the strain-hardening rate was about $1000 \mathrm{MPa}$ in stage III. In contrast, the strain-hardening rate was approx. $3000 \mathrm{MPa}$ in stage III in the specimen annealed at $700{ }^{\circ} \mathrm{C}$.
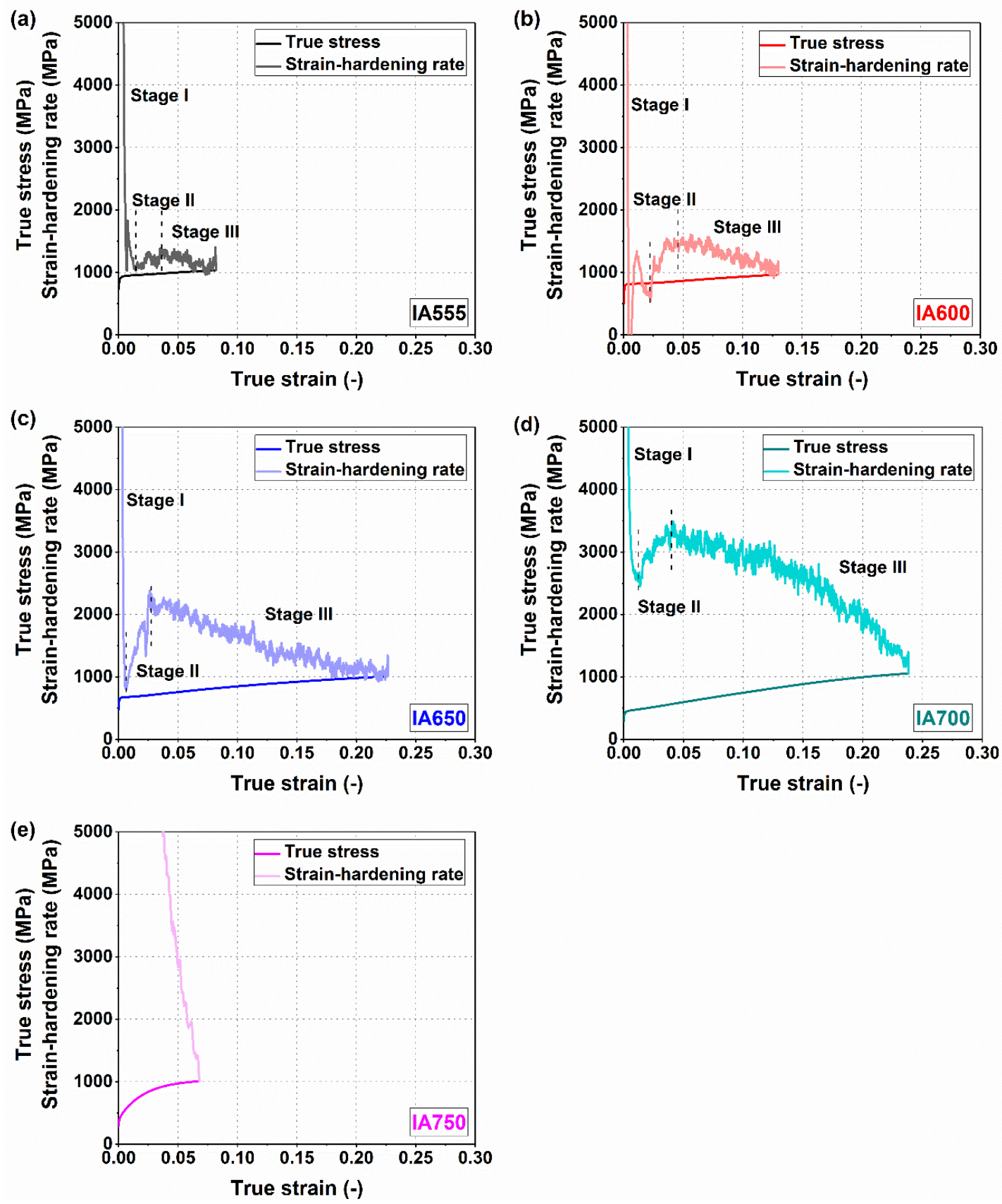

Figure 8. True stress-true strain curve and strain-hardening rate of (a) IA555 state; (b) IA600 state; (c) IA650 state; (d) IA700 state and (e) IA750 state. 


\subsection{Amount of Retained Austenite in the Deformed Specimens}

To evaluate mechanical stability of retained austenite, XRD measurements were performed after tensile deformation. The specimens were taken from the uniform elongation zone next to the necking regions. Figure 9a illustrates the XRD profiles of the medium-Mn steel after tensile deformation. In the specimen annealed at temperature up to $700{ }^{\circ} \mathrm{C}$, the austenite peaks remained, indicating the existence of retained austenite after deformation. In contrast, the austenite peaks completely disappeared in the specimens annealed at $750{ }^{\circ} \mathrm{C}$, meaning that all the retained austenite transformed into martensite during tensile deformation. Figure $9 \mathrm{~b}$ displays the amount of retained austenite and its transformation ratio in the specimens after tensile deformation as a function of intercritical annealing temperature. The austenite transformation ratio was defined by the change of austenite amount divided by austenite amount after intercritical annealing. More than $40 \mathrm{vol} \%$ of austenite remained in the specimens annealed up to $650{ }^{\circ} \mathrm{C}$, showing a transformation ratio lower than $10 \%$. It indicates a weak TRIP effect in the specimens during deformation. With a further increase in the intercritical annealing temperature, the austenite transformation ratio increased strongly. The progressive transformation of austenite into martensite was reported to enhance strain-hardening rate effectively in medium-Mn steels [3].
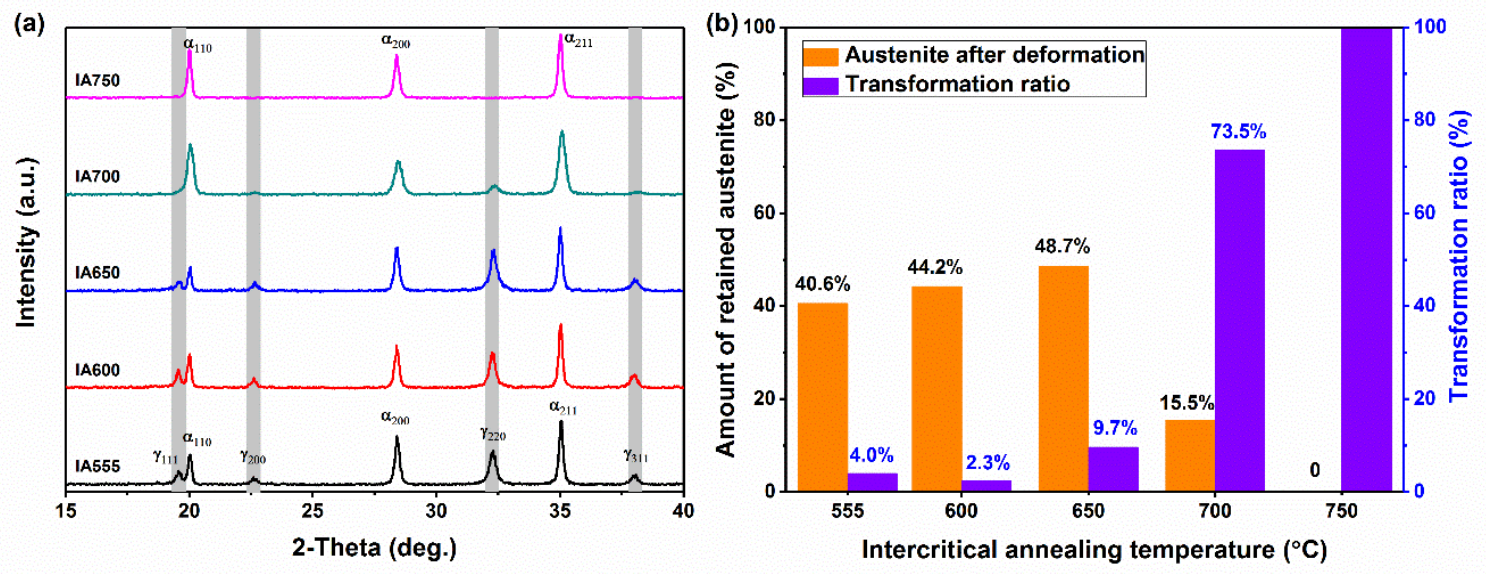

Figure 9. (a) XRD profiles of the medium-Mn steel Fe-12Mn-3Al-0.05C after tensile deformation; (b) the amount of retained austenite in the medium-Mn steel specimens after tensile deformation and its transformation ratio.

\section{Discussion}

\subsection{Influence of Intercritical Annealing Temperature on the Thermal Stability of Austenite and Deformation Mechanisms}

In the previous studies, it was stated that intercritical annealing has a great effect on austenite stability and deformation mechanisms in medium-Mn steels. The SFE seems to be one of the parameters in medium-Mn steels controlling the deformation mechanisms. On the one hand, it can be adjusted by the chemical composition as it is in high-Mn steels; on the other hand, it is strongly affected by intercritical annealing temperature. Different intercritical annealing temperature results in the different chemical composition of austenite due to elemental partitioning between austenite and ferrite.

In order to elucidate the thermal stability of austenite and deformation mechanisms in the medium-Mn steel, a thermodynamic approach was employed. The chemical composition Fe-11.7Mn-2.9Al-0.064C (wt \%) was used for the thermodynamic calculations. The amount and chemical composition of austenite under equilibrium condition were calculated using the Thermo-Calc package with TCFE9 database, as listed in Table 2. The martensite start $\left(M_{s}\right)$ temperature was calculated by the following equation [45]:

$$
M_{s}=547.58-596.914 \mathrm{C}-28.389 \mathrm{Mn}+8.827 \mathrm{Al}-60.5 V_{\gamma}^{-1 / 3}
$$


where, $\mathrm{C}, \mathrm{Mn}$, and $\mathrm{Al}$ is in weight percentage in austenite, $V_{\gamma}$ is the volume of the austenite grains. In the present work, the grain size of the austenite was assumed as $1 \mu \mathrm{m}$ in diameter for the calculation.

According to the prediction, the $M_{s}$ temperature was below room temperature when the intercritical annealing was carried out below $650{ }^{\circ} \mathrm{C}$. A further increase in intercritical annealing temperature led to an increase in the $M_{s}$ temperature above room temperature. When the $M_{s}$ temperature was higher than room temperature, the austenite with poor thermal stability might transform into $\alpha^{\prime}$-martensite upon quenching after intercritical annealing. Its fraction was predicted by the Koistinen-Marburger (KM) equation [45], as follows:

$$
f_{\alpha \prime}=1-\exp \left[-0.011\left(M_{s}-T\right)\right]
$$

The amount of retained austenite was calculated by subtracting the amount of fresh martensite from the amount of austenite under equilibrium condition, which is listed in Table 2. It can be seen that predicted amount of retained austenite increased with an increase in the intercritical annealing temperature from $555{ }^{\circ} \mathrm{C}$ to $650{ }^{\circ} \mathrm{C}$. It showed the same tendency as the amount of retained austenite measured by XRD (Figure $5 b$ ). Then the predicted amount of retained austenite dropped dramatically, when intercritical annealing temperature increased to $700{ }^{\circ} \mathrm{C}$ and $750{ }^{\circ} \mathrm{C}$, because of the improvised thermal stability of retained austenite. Although the predicted (Table 2) and measured (Figure 5b) amount of retained austenite showed the same tendency as a function of intercritical annealing temperature, there is some difference between them, especially at $700{ }^{\circ} \mathrm{C}$. In that case, it seems that the actual thermal stability of the retained austenite is higher than the predicted stability. This might be due to the effective stabilization of the austenite by UFG.

The SFE of retained austenite was calculated using the equilibrium chemical composition in austenite. The calculation was performed by an SFE calculator developed at the Steel Institute (IEHK) of RWTH Aachen University [46,47]. According to previous work, SFE $=20 \mathrm{~mJ} / \mathrm{m}^{2}$ is considered as the borderline between the TRIP and TWIP effects. When the SFE is below $20 \mathrm{~mJ} / \mathrm{m}^{2}$, the TRIP effect is dominant; whereas, the TWIP effect is the main deformation mechanism when SFE is above $20 \mathrm{~mJ} / \mathrm{m}^{2}$. Both the TRIP and TWIP effects are possible when the value of SFE is around the borderline. At a relatively low intercritical annealing temperature $\left(555^{\circ} \mathrm{C}\right.$ and $\left.600^{\circ} \mathrm{C}\right)$, the value of SFE was about $20 \mathrm{~mJ} / \mathrm{m}^{2}$ of retained austenite due to the strong partitioning of $\mathrm{Mn}$ and $\mathrm{C}$ into austenite. This value indicated a mixture of the TWIP and TRIP effects upon deformation [46,47]. With an increase in the intercritical annealing, the SFE decreased, indicating that only the TRIP effect might be the dominant mechanism during deformation. As shown by the XRD evaluation (Figure 9), the TRIP effect became more pronounced with an increase in intercritical annealing temperature.

Table 2. Thermodynamic prediction of the austenite chemical composition, the $M_{s}$ temperature, the microstructural constituents, the stacking fault energy (SFE) and the deformation mechanisms in retained austenite of the medium-Mn steel with chemical composition Fe-11.7Mn-2.9Al-0.064C (in wt $\%)$. IA: intercritical annealing, $M_{s}$ : martensite start, $\mathrm{M}_{\mathrm{F}}$ : fresh martensite, RA: retained austenite, TWIP: twinning-induced plasticity, TRIP: transformation-induced plasticity.

\begin{tabular}{|c|c|c|c|c|c|c|c|c|c|}
\hline \multirow{3}{*}{$\begin{array}{l}\text { IA Temp. } \\
\left({ }^{\circ} \mathrm{C}\right)\end{array}$} & \multicolumn{4}{|c|}{ Austenite under Equilibrium } & \multirow{3}{*}{$\begin{array}{l}M_{s} \text { Temp. } \\
\quad\left({ }^{\circ} \mathrm{C}\right)\end{array}$} & \multirow{3}{*}{$\begin{array}{l}\text { Amount of } \\
M_{F}(\operatorname{vol} \%)\end{array}$} & \multirow{3}{*}{$\begin{array}{l}\text { Amount of } \\
\text { RA (vol \%) }\end{array}$} & \multirow{3}{*}{$\begin{array}{c}\mathrm{SFE} \\
\left(\mathrm{mJ} / \mathrm{m}^{2}\right)\end{array}$} & \multirow{3}{*}{$\begin{array}{l}\text { Deformation } \\
\text { Mechanisms }\end{array}$} \\
\hline & \multirow{2}{*}{$\begin{array}{l}\text { Amount } \\
\text { (vol \%) }\end{array}$} & \multicolumn{3}{|c|}{ Chemistry, Fe Bal. (wt \%) } & & & & & \\
\hline & & $\mathrm{C}$ & Mn & Al & & & & & \\
\hline 555 & 43 & 0.150 & 21.8 & 2.1 & -218 & 0 & 43 & 24 & TWIP/TRIP \\
\hline 600 & 52 & 0.123 & 18.5 & 2.3 & -106 & 0 & 52 & 18 & TWIP/TRIP \\
\hline 650 & 64 & 0.099 & 15.3 & 2.5 & -2 & 0 & 64 & 13 & TRIP \\
\hline 700 & 79 & 0.081 & 13.2 & 2.7 & 72 & 40 & 39 & 11 & TRIP \\
\hline 750 & 97 & 0.066 & 11.9 & 2.9 & 121 & 65 & 32 & 10 & TRIP \\
\hline
\end{tabular}




\subsection{Influence of Intercritical Annealing Temperature on Microstructure and Mechanical Properties of the Medium-Mn Steel}

During the intercritical annealing of the medium-Mn steel Fe-12Mn-3Al-0.05C, not only does the austenite reverse transformation take place, but the microstructure recrystallization may occur in the cold-rolled medium-Mn steel as well. The occurrence of recrystallization might be responsible for the morphology difference in the medium-Mn steel annealed at different temperatures. Based on the results obtained in the present study, the influence of the intercritical annealing temperature on the microstructure and mechanical property features of the cold-rolled medium-Mn steel (Figure 10) is discussed below.

The microstructure of the cold-rolled material was deformed $\alpha^{\prime}$-martensite and it was brittle, showing intensely high strength of $1400 \mathrm{MPa}$ with little ductility (Figure 10a). The annealing of the cold-rolled medium-Mn steel within the intercritical region led to austenite reversion. In this way, duplex microstructure formed, which consisted of ferrite and a large amount of austenite. At the same time, the intercritical annealing resulted in a softening of the material with improved ductility. In previous studies, it was pointed out the intercritical annealing temperature has a great effect on the fraction and stability of retained austenite [10,48-52]. Consequently, the mechanical properties showed a strong dependence on intercritical annealing temperature (Figure 10). In addition to the dependence of the fraction and stability of retained austenite on intercritical annealing temperature, we found in the present study that the morphology of the cold-rolled medium-Mn closely relies on intercritical annealing temperature as well.

When the intercritical annealing was carried out below recrystallization temperature, the austenite and ferrite showed an elongated morphology (Figure 10b), which inherited the morphology of deformed $\alpha^{\prime}$-martensite. In this case, the morphology of cold-rolled medium-Mn steels is similar to that of hot-rolled medium-Mn steels [36-41]. It was most likely due to the sluggish recovery and recrystallization at the low annealing temperature. This favored the storage of high GND density in the microstructure from cold-rolled $\alpha^{\prime}$-martensite. Therefore, the steel possessed continuous yielding behavior with relatively high yield strength. However, the low intercritical annealing temperature resulted in stable retained austenite, which was difficult to transform into martensite or twins during deformation $[27,28]$. Hence, the steel exhibited a low strain-hardening rate with limited elongation.

(a)

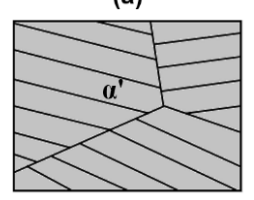

Cold-rolled (b)

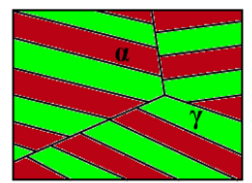

(c)

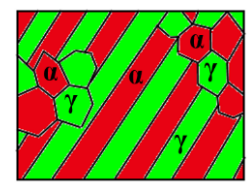

(d)

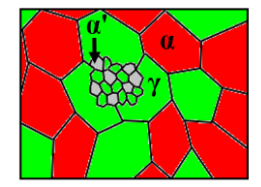

(e)

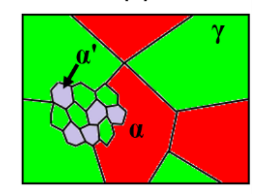

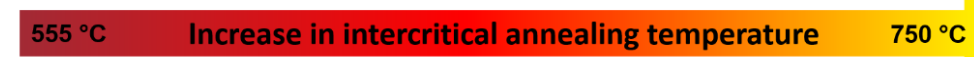

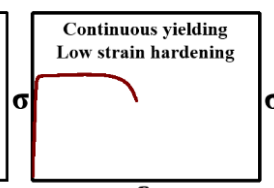

$\varepsilon$

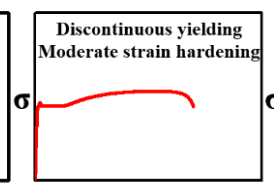

$\varepsilon$

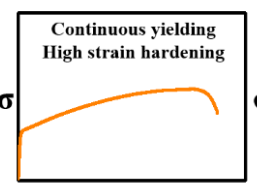

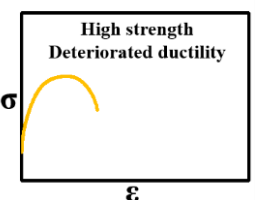

$\boldsymbol{\varepsilon}$

Figure 10. Schematic sketches of the microstructure and mechanical property characteristics of the cold-rolled medium-Mn steel in (a) cold-rolled state and (b-e) intercritically annealed state as a function of intercritical annealing temperature.

An increase in the intercritical annealing temperature facilitated recrystallization in the cold-rolled medium-Mn steel. The activation of recrystallization led to a dramatic reduction in the dislocation density in the microstructure. As a result, the steel possessed decreased yield strength and discontinuous yielding behavior (Figure 10c). The localized deformation was reported to be due 
to the UFG ferrite grain size and the lack of the strain hardening $[7,8,27]$. Besides, the amount of austenite increased and austenite stability declined with an increase in the annealing temperature. A decrease in the mechanical stability of austenite resulted in improved strain-hardening behavior and ductility $[8,27]$.

When the intercritical annealing temperature was further increased, ferrite and austenite were fully recrystallized, showing equiaxed morphology (Figure 10d), which was generally obtained in cold-rolled medium-Mn steels in the literature $[8,15,37,40,41,53]$. This equiaxed morphology in cold-rolled medium-Mn steels was explained by the recrystallization. Due to an increase in the recrystallization degree at a higher temperature, the yield strength of the material further dropped. However, a relatively high intercritical annealing temperature might lead to some fresh martensite formation during quenching in the thermally unstable austenite. The formation of the fresh martensite islands brought mobile dislocations in the microstructure, which might be responsible for the continuous yielding behavior [27]. In addition, the optimal mechanical stability of austenite promoted a large amount of retained austenite to progressively transform into martensite, namely the TRIP effect, which effectively enhanced the strain-hardening behavior and ductility [3].

A further increase in the intercritical annealing temperature led to the formation of a considerable amount of fresh martensite in the microstructure during quenching (Figure 10e). Apart from the poor thermal stability, the austenite possessed deteriorated mechanical stability as well. The stress-induced martensite transformation might take place during elastic deformation and austenite transforms into martensite rapidly during plastic deformation $[27,54]$, which was indicated by the extremely high strain-hardening rate.

\section{Conclusions}

In the present study, the influence of intercritical annealing temperature on the microstructure and mechanical properties of a cold-rolled medium-Mn steel Fe-12Mn-3Al-0.05C was investigated. The following conclusions have been drawn:

1. The intercritical annealing temperature has a great influence on the microstructure of the cold-rolled medium-Mn steel, in terms of amount and stability of retained austenite, as well as the microstructural morphology. As a consequence, the mechanical properties exhibit a strong dependence on the intercritical annealing temperature.

2. The intercritical annealing at $555{ }^{\circ} \mathrm{C}$ below recrystallization temperature results in the duplex microstructure of ferrite and austenite both with an elongated morphology, which inherits the lath structure of the cold-rolled steels.

3. An increase in intercritical annealing temperature leads to the activation of recrystallization, indicated by the duplex microstructure with an equiaxed morphology.

4. The relatively high austenite stability obtained at low intercritical annealing temperature $\left(555^{\circ} \mathrm{C}\right)$ results in a low strain-hardening rate, whereas an increase in the intercritical annealing temperature up to $700{ }^{\circ} \mathrm{C}$ leads to an increase in strain-hardening rate and ductility in the medium-Mn steel, which is due to the effective TRIP effect.

5. Intercritical annealing at the very high temperature $\left(750^{\circ} \mathrm{C}\right)$ leads to a decrease in both thermal and mechanical stability of austenite and a deterioration of the mechanical properties.

Author Contributions: Y.M. and W.S. designed the experiments. Y.M. and S.Z. analyzed the SEM, XRD and mechanical properties data. A.S. performed the EBSD measurements and analyzed the data. W.B. contributed with ideas and intensive discussions. All authors contributed to the interpretation of the results and the writing of the final version of the manuscript.

Acknowledgments: The authors gratefully acknowledge the financial support of the Deutsche Forschungsgemeinschaft (DFG) within the Collaborative Research Center (SFB) 761 'Steel-ab initio: Quantum mechanics guided design of new Fe-based materials'. Björn Faßbänder's support of XRD measurements in the Institute of Inorganic Chemistry at RWTH Aachen University is gratefully acknowledged.

Conflicts of Interest: The authors declare no conflict of interest. 


\section{References}

1. Bouaziz, O.; Zurob, H.; Huang, M. Driving force and logic of development of advanced high strength steels for automotive applications. Steel Res. Int. 2013, 12, 937-947. [CrossRef]

2. Matlock, D.K.; Speer, J.G.; De Moor, E.; Gibbs, P.J. Recent developments in advanced high strength sheet steels for automotive applications: An overview. Jestech 2012, 15, 1-12.

3. Bleck, W.; Guo, X.; Ma, Y. The TRIP Effect and Its Application in Cold Formable Sheet Steels. Steel Res. Int. 2017, 88, 1700218. [CrossRef]

4. Matlock, D.K.; Speer, J.G. Third generation of AHSS: Microstructure design concepts. In Microstructure and Texture in Steels; Haldar, A., Suwas, S., Bhattacharjee, D., Eds.; Springer: London, UK, 2009; pp. 185-205.

5. De Cooman, B.C.; Estrin, Y.; Kim, S.K. Twinning-induced plasticity (TWIP) steels. Acta Mater. 2018, 142, 283-362. [CrossRef]

6. Bouaziz, O.; Allain, S.; Scott, C.P.; Cugy, P.; Barbier, D. High manganese austenitic twinning induced plasticity steels: A review of the microstructure properties relationships. Curr. Opin. Solid State Mater. Sci. 2011, 15, 141-168. [CrossRef]

7. Ma, Y. Medium-manganese steels processed by austenite-reverted-transformation annealing for automotive applications. Mater. Sci. Technol. 2017, 33, 1713-1727. [CrossRef]

8. Miller, R.L. Ultrafine-grained microstructures and mechanical properties of alloy steels. Metall. Mater. Trans. B 1972, 3, 905-912. [CrossRef]

9. Lee, S.; De Cooman, B.C. On the selection of the optimal intercritical annealing temperature for medium $\mathrm{mn}$ TRIP steel. Metall. Mater. Trans. A 2013, 44, 5018-5024. [CrossRef]

10. Gibbs, P.J.; de Moor, E.; Merwin, M.J.; Clausen, B.; Speer, J.G.; Matlock, D.K. Austenite stability effects on tensile behavior of manganese-enriched-austenite transformation-induced plasticity steel. Metall. Mater. Trans. A 2011, 42, 3691-3702. [CrossRef]

11. Cao, W.; Wang, C.; Shi, J.; Wang, M.; Hui, W.; Dong, H. Microstructure and mechanical properties of Fe-0.2C-5Mn steel processed by ART-annealing. Mater. Sci. Eng. A 2011, 528, 6661-6666. [CrossRef]

12. Haupt, M.; Dutta, A.; Ponge, D.; Sandlöbes, S.; Nellessen, M.; Hirt, G. Influence of Intercritical Annealing on Microstructure and Mechanical Properties of a Medium Manganese Steel. Procedia Eng. 2017, 207, 1803-1808. [CrossRef]

13. Suh, D.W.; Park, S.-J.; Lee, T.-H.; Oh, C.-S.; Kim, S.-J. Influence of Al on the Microstructural Evolution and Mechanical Behavior of Low-Carbon, Manganese Transformation-Induced-Plasticity Steel. Metall. Mater. Trans. A 2010, 41, 397-408. [CrossRef]

14. Choi, H.; Lee, S.; Lee, J.; Barlat, F.; De Cooman, B.C. Characterization of fracture in medium Mn steel. Mater. Sci. Eng. A 2017, 687, 200-210. [CrossRef]

15. Lee, S.; De Cooman, B.C. Annealing temperature dependence of the tensile behavior of 10 pct Mn multi-phase TWIP-TRIP steel. Metall. Mater. Trans. A 2014, 45, 6039-6052. [CrossRef]

16. Sun, B.; Fazeli, F.; Scott, C.; Brodusch, N.; Gauvin, R.; Yue, S. The influence of silicon additions on the deformation behavior of austenite-ferrite duplex medium manganese steels. Acta Mater. 2018, 148, $249-262$. [CrossRef]

17. Shi, J.; Sun, X.; Wang, M.; Hui, W.; Dong, H.; Cao, W. Enhanced work-hardening behavior and mechanical properties in ultrafine-grained steels with large-fractioned metastable austenite. Scr. Mater. 2010, 63, 815-818. [CrossRef]

18. Suh, D.-W.; Kim, S.-J. Medium Mn transformation-induced plasticity steels: Recent progress and challenges. Scr. Mater. 2017, 126, 63-67. [CrossRef]

19. Lee, Y.-K.; Han, J. Current opinion in medium manganese steel. Mater. Sci. Technol. 2015, 31, $843-856$. [CrossRef]

20. Bugat, S.; Besson, J.; Gourgues, A.-F.; N’Guyen, F.; Pineau, A. Microstructure and damage initiation in duplex stainless steels. Mater. Sci. Eng. A 2001, 317, 32-36. [CrossRef]

21. Bugat, S.; Besson, J.; Pineau, A. Micromechanical modeling of the behavior of duplex stainless steels. Comput. Mater. Sci. 1999, 16, 158-166. [CrossRef]

22. Knobbe, H.; Starke, P.; Hereñú, S.; Christ, H.-J.; Eifler, D. Cyclic deformation behaviour, microstructural evolution and fatigue life of duplex steel AISI 329 LN. Int. J. Fatigue 2015, 80, 81-89. [CrossRef] 
23. Lo, K.H.; Shek, C.H.; Lai, J.K.L. Recent developments in stainless steels. Mater. Sci. Eng. R Rep. 2009, 65, 39-104. [CrossRef]

24. Lee, S.; De Cooman, B.C. Tensile behavior of intercritically annealed ultra-fine grained $8 \%$ Mn multi-phase steel. Steel Res. Int. 2015, 86, 1170-1178. [CrossRef]

25. Luo, H.; Dong, H.; Huang, M. Effect of intercritical annealing on the Lüders strains of medium Mn transformation-induced plasticity steels. Mater. Des. 2015, 83, 42-48. [CrossRef]

26. Lee, S.; De Cooman, B.C. Effect of the intercritical annealing temperature on the mechanical properties of 10 pct Mn multi-phase steel. Metall. Mater. Trans. A 2014, 45, 5009-5016. [CrossRef]

27. Lee, S.; Lee, S.-J.; Santhosh K, S.; Lee, K.; De Cooman, B.C. Localized deformation in multiphase, ultra-fine-grained 6 pct Mn transformation-induced plasticity steel. Metall. Mater. Trans. A 2011, 42, 3638-3651. [CrossRef]

28. Suh, D.W.; Ryu, J.H.; Joo, M.S.; Yang, H.S.; Lee, K.; Bhadeshia, H.K.D.H. Medium-alloy manganese-rich transformation-induced plasticity steels. Metall. Mater. Trans. A 2013, 44, 286-293. [CrossRef]

29. Luo, H.; Shi, J.; Wang, C.; Cao, W.; Sun, X.; Dong, H. Experimental and numerical analysis on formation of stable austenite during the intercritical annealing of 5Mn steel. Acta Mater. 2011, 59, 4002-4014. [CrossRef]

30. Han, J.; Lee, S.-J.; Jung, J.-G.; Lee, Y.-K. The effects of the initial martensite microstructure on the microstructure and tensile properties of intercritically annealed Fe-9Mn-0.05C steel. Acta Mater. 2014, 78, 369-377. [CrossRef]

31. Han, J.; Lee, S.-J.; Lee, C.-Y.; Lee, S.; Jo, S.Y.; Lee, Y.K. The size effect of initial martensite constituents on the microstructure and tensile properties of intercritically annealed Fe-9Mn-0.05C steel. Mater. Sci. Eng. A 2015, 633, 9-16. [CrossRef]

32. Han, J.; Lee, Y.-K. The effects of the heating rate on the reverse transformation mechanism and the phase stability of reverted austenite in medium Mn steels. Acta Mater. 2014, 67, 354-361. [CrossRef]

33. Zhao, C.; Zhang, C.; Cao, W.; Yang, Z.; Dong, H.; Weng, Y. Austenite thermal stabilization through the concentration of manganese and carbon in the 0.2C-5Mn steel. ISIJ Int. 2014, 54, 2875-2880. [CrossRef]

34. Wang, C.; Shi, J.; Hui, W.; Wang, M.; Dong, H.; Cao, W. Development of ultrafine lamellar ferrite and austenite duplex structure in 0.2C5Mn steel during ART-annealing. ISIJ Int. 2011, 51, 651-656. [CrossRef]

35. Dong, H.; Cao, W.; Shi, J. Formation of an ultrafine-grained austenite-containing microstructure from a cold-rolled medium-manganese steel processed using intercritical annealing. Mater. Sci. Forum 2013, 762, 31-37. [CrossRef]

36. He, B.; Luo, H.; Huang, M. Experimental investigation on a novel medium Mn steel combining transformation-induced plasticity and twinning-induced plasticity effects. Int. J. Plast. 2016, 78, 173-186. [CrossRef]

37. Sun, R.; Xu, W.; Wang, C.; Shi, J.; Dong, H.; Cao, W. Work hardening behavior of ultrafine grained duplex medium-Mn steels processed by ART-annealing. Steel Res. Int. 2012, 83, 316-321. [CrossRef]

38. Shao, C.; Hui, W.; Zhang, Y.; Zhao, X.; Weng, Y. Microstructure and mechanical properties of hot-rolled medium-Mn steel containing 3\% aluminum. Mater. Sci. Eng. A 2017, 682, 45-53. [CrossRef]

39. Tsuchiyama, T.; Inoue, T.; Tobata, J.; Akama, D.; Takaki, S. Microstructure and mechanical properties of a medium manganese steel treated with interrupted quenching and intercritical annealing. Scr. Mater. 2016, 122, 36-39. [CrossRef]

40. Han, J.; Kwiatkowski da Silva, A.; Ponge, D.; Raabe, D.; Lee, S.-M.; Lee, Y.-K.; Lee, S.-I.; Hwang, B. The effects of prior austenite grain boundaries and microstructural morphology on the impact toughness of intercritically annealed medium Mn steel. Acta Mater. 2017, 122, 199-206. [CrossRef]

41. Hu, B.; Luo, H. Microstructures and mechanical properties of $7 \mathrm{Mn}$ steel manufactured by different rolling processes. Metals 2017, 7, 464. [CrossRef]

42. Cai, Z.; Ding, H.; Misra, R.D.K.; Ying, Z. Austenite stability and deformation behavior in a cold-rolled transformation-induced plasticity steel with medium manganese content. Acta Mater. 2015, 84, 229-236. [CrossRef]

43. Lee, S.; De Cooman, B.C. Tensile behavior of intercritically annealed 10 pct Mn multi-phase steel. Metall. Mater. Trans. A 2014, 45, 709-716. [CrossRef]

44. De Meyer, M.; Vanderschueren, D.; De Blauwe, K.; De Cooman, B.C. The characterization of retained austenite in TRIP steels by X-ray diffraction. In Proceedings of the ISS, 41st Mechanical Working and Steel Processing Conference, Baltimore, MD, USA, 24-27 October 1999; Volume XXXXVII, pp. 265-276. 
45. Lee, S. Contribution to the Physical Metallurgy of Ultrafine-Grained Medium Mn TRIP Steel. Ph.D. Thesis, Pohang University of Science and Technology, Pohang, Korea, 2015.

46. Saeed-Akbari, A.; Imlau, J.; Prahl, U.; Bleck, W. Derivation and variation in composition-dependent stacking fault energy maps based on subregular solution model in high-manganese steels. Metall. Mater. Trans. A 2009, 40, 3076-3090. [CrossRef]

47. Song, W.; Ingendahl, T.; Bleck, W. Control of strain hardening behavior in high-Mn austenitic steels. Acta Metall. Sin. 2014, 27, 546-556. [CrossRef]

48. Callahan, M.; Hubert, O.; Hild, F.; Perlade, A.; Schmitt, J. Coincidence of strain-induced TRIP and propagative PLC bands in Medium Mn steels. Mater. Sci. Eng. A 2017, 704, 391-400. [CrossRef]

49. Lee, S.; Lee, K.; De Cooman, B.C. Observation of the TWIP + TRIP plasticity-enhancement mechanism in Al-added 6 wt pct medium Mn steel. Metall. Mater. Trans. A 2015, 46, 2356-2363. [CrossRef]

50. Li, Z.; Ding, H.; Misra, R.D.K.; Cai, Z. Deformation behavior in cold-rolled medium-manganese TRIP steel and effect of pre-strain on the Lüders bands. Mater. Sci. Eng. A 2017, 679, 230-239. [CrossRef]

51. Yang, F.; Luo, H.; Hu, C.; Pu, E.; Dong, H. Effects of intercritical annealing process on microstructures and tensile properties of cold-rolled 7Mn steel. Mater. Sci. Eng. A 2017, 685, 115-122. [CrossRef]

52. Moor, E.D.; Matlock, D.K.; Speer, J.G.; Merwin, M.J. Austenite stabilization through manganese enrichment. Scr. Mater. 2011, 64, 185-188. [CrossRef]

53. Emo, J.; Maugis, P.; Perlade, A. Austenite growth and stability in medium Mn, medium Al Fe-C-Mn-Al steels. Comput. Mater. Sci. 2016, 125, 206-217. [CrossRef]

54. Ryu, J.H.; Kim, J.I.; Kim, H.S.; Oh, C.-S.; Bhadeshia, H.K.D.H.; Suh, D.-W. Austenite stability and heterogeneous deformation in fine-grained transformation-induced plasticity-assisted steel. Scr. Mater. 2013, 68, 933-936. [CrossRef]

(C) 2018 by the authors. Licensee MDPI, Basel, Switzerland. This article is an open access article distributed under the terms and conditions of the Creative Commons Attribution (CC BY) license (http:/ / creativecommons.org/licenses/by/4.0/). 